\title{
FIM DE LINHA NA ARTE: PINTORES RETRATISTAS DE RUA*
}

Lígia Dabul

Rodrigo Barreto

No estudo da chamada arte erudita, ou de elite, ou daquela que ampla e simplesmente apresentamos como arte, costuma fugir de nossos interesses o que parece não dar certo. Seguindo de perto o senso comum, nossas formas de pensá-la em geral estão voltadas para atores sociais bem-sucedidos e objetos de alguma maneira consagrados, o que acaba por ajudar a separar a arte e seus produtores do reino supostamente imperfeito e ordinário do resto dos produtos humanos e da própria humanidade. ${ }^{1}$

No estudo da chamada arte popular também ficamos mais à vontade enfocando tanto objetos valorizados extensamente entre nós como os artistas que conseguiram se afirmar, neste caso, como artistas populares. Em certa medida, alguns pressupostos, além dos que operam na abordagem da arte de elite, conduzem essa preferência, como o fato de a arte popular ser com frequência concebida como fixação de ditames de entidades cultuadas, como Povo, Cultura, Tradição, e/ou como atualização de padrões por meio de técnicas, isto é, regada por facilidades e, por isso, algo defendida do erro. Outra ideia que acompanha a primazia do êxito na análise sociológica da arte é a que associa a prática artística ao lugar social dos produtores da arte, sua correspondência com a organização social estabelecendo que são os atributos sociais, prévia e indubitavelmente definidos, que levarão os indivíduos a serem artistas populares e a produzirem arte tal como os demais indivíduos dotados daqueles atributos. ${ }^{2}$ E, ainda, quando fugimos dessa coincidência da arte com a organização social e singularizamos os "artistas populares" pelo reconhecimento da excelência de seus trabalhos, sua capacidade de produzir arte tende a aparecer como dom inato, algo que vem "de dentro" do artista, dado como nascido e portado por ele, naturalmente "materializado" em obras dignas de serem tratadas como arte.

Em resumo, é difícil pensar a arte pela via do insucesso e da frustração, o que por certo nos desvia de considerável parte do que ela sociologicamente encerra de importante. Apresentando o caso que estudamos, de artistas 
plásticos que trabalham pintando retratos nas ruas do Rio de Janeiro e que têm como pouso mais frequente o Largo da Carioca, no centro da cidade, pretendemos trazer para a análise a dificuldade que não raro atores sociais encontram para constituir e manter sua condição de artistas. Com este intuito, enfatizamos dimensões da arte em geral ou não abordadas nos estudos sobre artistas plásticos, ou tratadas sem que tensões que as compõem sejam levadas em conta. Consideraremos, por exemplo, o caráter não unívoco das configurações que as práticas artísticas assumem, e o quanto em determinados contextos a convivência entre elas é especialmente problemática. Também tentaremos salientar os vínculos entre experiências da arte aparentemente incomunicáveis, acompanhando trajetórias de artistas por espaços sociais muito distanciados. Finalmente, estendendo o âmbito das conexões entre artistas e os atores sociais que de alguma forma avaliam seu trabalho, teremos em conta algumas propriedades das relações entre artistas e clientes, marcando a oportunidade de tomá-las como constitutivas da arte.

Para tanto, vamos descrever e refletir sobre uma situação na qual artistas plásticos que trabalham pintando retratos nas ruas do Rio de Janeiro experimentam profunda e prolongada frustração com sua arte, e permanecem envolvidos na sua produção ainda que em condições que consideram adversas. Em um primeiro momento faremos breve apresentação do grupo de pouco mais de uma dezena de retratistas que estudamos e que inclui alguns artistas plásticos, e indicaremos o quanto compreender certas insatisfações suas pode nos levar a questões interessantes de pesquisa. Em seguida, procederemos ao enfoque de distinção que compõe o objeto estudado - aquele que especifica os artistas plásticos diante de outros trabalhadores com quem compartilham espaço de trabalho e disputam clientela, em proximidade que aponta e atesta, para eles, a ambígua e inadequada posição em que se encontram. Mais adiante, descreveremos algo das condições daqueles que tais artistas consideram desqualificados para um trabalho frequentemente confundido com o seu. No item seguinte, seguiremos suas referências ao lugar das suas relações com clientes nas avaliações que fazem das condições que encontram para criar. E então apresentaremos algumas implicações de inserirmos no estudo da arte essas experiências de descontentamento e falta de perspectivas por parte daqueles que a produzem e têm suas vidas voltadas para ela.

\section{Ambulantes e retratistas}

Em 2009, conduzidos pela Operação Choque de Ordem, ${ }^{3}$ os retratistas que vendiam - e por vezes faziam - seus trabalhos na calçada da Av. Rio 
Branco, na altura da Carioca, centro da cidade do Rio de Janeiro, Brasil, foram deslocados para uma área perto dali, cercada por grades, no entorno do Convento de Santo Antonio. Depois da mudança, os retratistas viram ficar bastante reduzido o número de clientes, antes alimentado por turistas e pelo fluxo considerável de transeuntes daquela avenida, uma das mais movimentadas da cidade. Classificados pela Prefeitura como "ambulantes", eles convivem agora com esses outros trabalhadores, também conhecidos como camelôs, que vendem produtos em espaços públicos.

O trabalho desses retratistas inclui exporem naquele espaço retratos já feitos ou em elaboração, e a espera de clientes que se interessem em encomendar algum. Conta também com a abordagem de passantes aos quais oferecem seu produto, que consiste em geral em cópia ampliada de fotografia fornecida pelo interessado - dele mesmo ou de alguém de suas relações ou ainda de imagem de personalidade famosa - ator, cantor, jogador de futebol etc. - da qual queira reprodução. Por vezes são solicitadas cópias em tamanho aumentado de algum personagem de ficção, por exemplo, de desenhos animados. O preço cobrado varia em função do tempo a ser investido e do custo do material a ser gasto no retrato encomendado - carvão, tinta a óleo, acrílica, pastel, suporte de tela ou de cartão - proporcional de alguma maneira à sua dimensão.

Para a maioria dos transeuntes, os trabalhos dos diferentes retratistas não têm significativas variações, afora alguma flutuação no preço, ainda que, certamente, o cuidado com o acabamento, a beleza imprimida aos retratados e, quando é o caso, também a semelhança em relação às personalidades ou aos personagens reproduzidos sejam objetos de avaliação. De fato, se comparamos as fotografias que servirão de modelos entregues aos retratistas e o resultado a que chegam, constataremos que lidam, todos eles, com difícil dosagem e por vezes tensão entre beleza e parecença. Rugas e cicatrizes costumam ser suprimidas dos trabalhos. Ternos são pintados em retratos de senhores que nas fotos se exibem de camiseta. Mulheres têm seus cabelos ajeitados. Mas, sempre, o resultado deve consistir em cópia - se não incontestável, ao menos convincente - do modelo a ser reconhecido com facilidade pelo contratante. ${ }^{4}$

Nós também, se partíssemos do produto do trabalho que esses retratistas anunciam, vendem e por vezes confeccionam naquele espaço, dificilmente estabeleceríamos distinções significativas entre eles. Talvez também não estranhássemos que estivessem ali com o produto de seu trabalho tal como estão os ambulantes que ocupam com eles aquele espaço engradado e comercializam eventualmente artesanato feito por eles mesmos ou por terceiros ao lado de bancas com produtos industrializados. A forma diversificada, entre 
os próprios retratistas, de lidar com essas difundidas indistinções consiste em índice contundente das diferenças que atribuem a seus trabalhos e à situação de estarem ali. São por isso condutos eficazes para nos perguntarmos sobre as muitas configurações - nem sempre experimentadas com contentamento - que a arte e seus produtos assumem para as pessoas envolvidas, algumas muito atadas a ela.

\section{Retratistas, pintores}

Neste caso específico que estudamos, há como indagarmos acerca da correspondência entre as trajetórias sociais e os significados, bastante diferenciados, que retratistas efetivamente conferem às atividades que exercem naquele espaço - questão improvável quando afastamos a análise da arte como trabalho da análise da arte como produção simbólica. ${ }^{5}$ Alguns retratistas não se incomodam com a classificação de "ambulantes" dada pela Prefeitura, indignando-se, isso sim, com a proibição de continuarem a ocupar a calçada da av. Rio Branco nas imediações do acesso principal à Estação Carioca do metrô do Rio, onde preferencialmente se instalavam antes daquela operação da Prefeitura que os fixou nas proximidades do convento. Na verdade, todos os retratistas ressentiram-se da perda de freguesia, mas alguns deles, além disso, ficaram particularmente ofendidos com a sua equiparação oficial aos camelôs.

O grupo de cerca de 13 retratistas $^{6}$ que costuma estar no Largo da Carioca durante a semana pouco se fala. Ele consiste em um agregado de indivíduos que convive quase diariamente sem que interaja de maneira significativa. Nem no momento da transferência da calçada da Rio Branco para a cercania do convento se uniram para enfrentar as determinações da Prefeitura. A impressão de tratar-se de grupo amorfo, somatório de indivíduos sem grande identidade ou diferenciação interna — impressão reforçada pela sensação de que os retratos que confeccionam são equiparáveis - contrasta com o grande incômodo que apenas alguns deles demonstraram em serem classificados como camelôs.

Os quatro retratistas mais velhos, que têm entre 45 e 56 anos, ${ }^{7}$ afastam com veemência qualquer possibilidade de serem confundidos com ambulantes. E, segundo o que disseram, não fazem nem vendem retratos, mas pinturas, ainda que por vezes possam referir-se a elas como pinturas de retratos; e consideram-se, segundo afirmaram, ou retratistas ou pintores, não pintores de retratos, como os demais que ali estão por vezes se autodenominam. ${ }^{8}$

Os quatro tiveram formação prolongada em artes plásticas, estudando na graduação da Escola de Belas Artes da Universidade Federal do Rio de 
Janeiro, dois deles conseguindo finalizar o curso, não sem grandes esforços e percalços. Porque suas famílias não possuíam recursos para que se dedicassem exclusivamente à faculdade de artes, nem para que tivessem acesso ao material exigido, para eles caríssimo, nunca desfrutaram, mesmo os que se diplomaram, das mesmas condições que os colegas para acompanhar o curso. Todos eles trabalharam praticamente ao longo de todo o tempo em que cursaram a universidade, embora contassem com intenso apoio familiar para que pudessem continuar os estudos. O fato de trabalharem gerava atrasos, cansaço e limites para a concentração nas tarefas do curso, levando-os à sua interrupção ou a um excessivo prolongamento, frequentes abandonos ou trancamentos de disciplinas. Os quatro, além do inacessível que era a compra do extenso material para acompanhar as aulas, também não conseguiam adquirir os livros adotados que, na sua maioria, não são encontrados na biblioteca da Escola de Belas Artes.

Nos seus relatos sobre suas experiências no curso, associam tais dificuldades a uma orientação da escola e, mesmo, a uma atitude dos professores - demanda de material, de leituras e pontualidade, de exercícios, de disponibilidade - insensíveis às condições de estudo dos — bem poucos alunos pobres. E afirmam que, na verdade, aquele era um curso voltado para e frequentado pelo "pessoal da elite carioca", de quem se sentiam distanciados já pela forma como se vestiam, se comportavam, divertiam-se, o que os localizava claramente, restringindo até seu acesso a eventos e contatos. Haveria ali correlação importante entre a percepção da origem social de um indivíduo e o valor atribuído à sua produção artística. Para eles, isso concorreu para que não se afirmassem como artistas naquele ambiente, para além da dificuldade material de investirem em viagens, na participação em exposições, na criação de seu ateliê ou local próprio para a produção de seus trabalhos, como alguns colegas tinham "até no exterior".9

Depreende-se de seus relatos que havia, ainda, nítida impossibilidade de se verem reconhecidos por não disporem de capital social, uma vez que não tinham como mobilizar relações sociais para que seu trabalho fosse aceito por aqueles que poderiam situá-los como artistas - críticos, colecionadores, jornalistas, estudiosos, artistas consagrados, compradores etc. - com os quais seus colegas, ou os familiares ou amigos de seus colegas, mantinham algum tipo de proximidade ou interação. Contudo, se não puderam constituir uma carreira artística como diversos dos colegas, esses artistas inseriram-se em mercado de trabalho atrelado ao próprio funcionamento da Escola de Belas Artes e ao trabalho e à constituição da carreira dos professores e alunos: "Eu estudava de manhã, depois eu ia trabalhar numa lanchonete [...]. Fiz isso por muito tempo, depois comecei a trabalhar com uns professores na 
faculdade. Mas era peão mesmo. Carregava quadro, chassi, ajudava na iluminação, carregava as coisas de um lado pro outro".

Em seguida ao curso, acabado ou após desistirem de terminá-lo, de forma intermitente mas por toda a vida e insistentemente, praticaram atividades ligadas diretamente ao métier - ministraram cursos de artes em escolas e outras instituições, deram aulas particulares de artes plásticas, atuaram como assistentes de artistas plásticos consagrados, fizeram esculturas, pintaram réplicas de quadros famosos e suas próprias criações, e alguns chegaram a ter por curto período seus ateliês - e em áreas que consideravam afins, como cenografia. Trabalhar com a pintura de retratos na rua aparece como opção que abraçaram em período especialmente difícil — por exemplo, na volta ao Rio depois de prolongado tempo vivendo em outra cidade - em geral por conselho ou a exemplo de algum amigo artista plástico que pintava retratos.

O retratismo praticado na rua parece ser atividade antiga no Rio de Janeiro e requisitada por moradores da cidade, sobretudo na modalidade preponderante no Largo da Carioca, efetuada por meio da cópia de fotos cedidas por quem encomenda o retrato. Mas associado à expansão do turismo no Rio de Janeiro ${ }^{10}$ e ao respectivo comércio de souvenirs, ${ }^{11}$ o retratismo vem se tornando comum nas últimas décadas também em locais de especial concentração de visitantes da cidade. Trata-se de trabalho há muitos anos exercido por esses e por tantos outros retratistas, nos mais diferentes lugares e por diferentes períodos, contando em geral com conjugação com outras atividades ${ }^{12}$ e com muita instabilidade.

Os retratistas com formação em artes com quem conversamos no Largo da Carioca contam histórias de retratistas que enriqueceram, como um pintor italiano que fazia retratos na Itália e "tirava um dinheirão e depois viajava o mundo". Contudo, ainda quando tratada como atividade que poderia oferecer retorno econômico interessante, o fato de ser exercido na rua os leva a pensar o retratismo como item do processo por meio do qual sua trajetória artística foi configurada. Então, em que pese ter proporcionado para eles até fartura em alguns contextos, trata-se de desfecho de tentativas de constituição de uma carreira artística sistemática e paulatinamente frustrada, indicação do limite irreversível, um fim, para os artistas que "não se deram bem".

Eu já passei por muita coisa e por muito canto. Já pintei retrato em São Paulo, em tudo quanto é praia - Búzios, Angra, Cabo Frio, Arraial. Já pintei retrato na Feira Hippie, aqui em Ipanema, e antigamente eu pintava lá embaixo no metrô. Só por aqui, no Centro, eu estou há quase 14 anos. Já ganhei muita grana, já tive muita necessidade, já torrei dinheiro que ganhava e já fiquei até sem comer. Mas você pode ter certeza de que quando um artista vai pra rua, 
é o fim da linha. Se você for lá entrevistar os meninos que tocam violino, você vai ver isso. É pessoal que faz palhaço, estátua viva, mágica, toca saxofone, não importa: é só gente que não se deu bem. ${ }^{13}$

Não terem se dado bem, explicam, é resultado da carência de contatos, de inserção no meio artístico, e da falta de recursos financeiros, uma continuidade do processo iniciado já na sua passagem pela universidade que os teria feito lançar mão da pintura de retratos nas ruas para sobreviver. E todos esses retratistas do Largo da Carioca com formação em artes plásticas relatam difíceis situações de iminência de abandonar o retratismo nas condições em que o exercem. Uma das razões que apontam para a persistência é o caráter autônomo dessa ocupação em face de outras possibilidades de trabalho que por vezes se colocam, como a de empregados no comércio, mas especialmente o vínculo direto dessa atividade com a arte: "Pintar é a minha vida, entende? Eu faço isso há quase 30 anos. Não consigo me imaginar fazendo outra coisa que não seja isso. Já viu jogador de futebol que não consegue parar? [...] Acho que vou morrer fazendo isso".

Para além das avaliações negativas que direcionam para a sua eventual equiparação com camelôs e outros retratistas não qualificados, eles compartilham com os demais retratistas do Largo da Carioca a insatisfação em relação aos ganhos com a venda de seus produtos e com as condições de trabalho que enfrentam. Todos reclamam do peso de estarem expostos a "chuva e sol", e contrastam a situação de "trabalhar na rua" com outras que consideram melhores. Sobretudo depois que foram para perto do convento, os retratistas com formação em artes estariam buscando condições de trabalho menos adversas, exercendo o próprio retratismo em lugares mais interessantes e apenas nos finais de semana, "para tirar um extra", ou outras atividades na área de artes, como dar aulas, particulares ou não, por exemplo, vinculando-se a ONGs.

Em graus diferentes, os retratistas do Largo da Carioca que tiveram formação em artes estão sempre dosando a busca pela intensificação de outras atividades artísticas e a manutenção do retratismo, responsável pela parcela mais importante do que obtêm para viver. Embora exercido em situação para eles precária, concebem o retratismo como modalidade de prática, tradicional nas artes plásticas, para a qual foram treinados, realizando-a com facilidade e qualidade em função da sua formação em desenho e pintura e do conhecimento do seu significado na história da arte. De fato, diferenciando-se dos outros retratistas com quem compartilham aquele espaço do Largo da Carioca e a sua clientela, afirmam que seus trabalhos possuem qualidade, apuro técnico, e mostram-se indignados quando se veem igualados a eles. 
Enfatizam haver profundas diferenças entre suas pinturas e as reproduções feitas pelos demais, desprovidos de cuidado e recursos técnicos e sem formação específica em arte, que oferecem trabalhos repletos de imperfeições: “Eu não cheguei aqui, pendurei uns quadros e disse que era pintor. Eu estudei, pintei muito retrato antes de vir para cá. Pintei paisagem, natureza morta. Não é de uma hora para outra não. Aí chega um aqui que nem sabe pintar direito e fala que é pintor".

Essa ideia de superioridade das suas formas de trabalho e dos objetos que produzem em face dos demais retratistas aparece com muita frequência associada à formação diferenciada, universitária à qual poucos teriam acesso. A afirmação de uma hierarquia de formas de aprendizado da pintura de retratos irá, de fato, sustentar muitos dos argumentos acionados por esses retratistas na demonstração do quão inoportuna é a presença dos demais pintores de retratos ali. Por outro lado, a negação de tal hierarquia por esses outros retratistas suscitará as muitas tentativas de se provar o oposto, como veremos mais à frente.

\section{Retratistas, pintores de retrato}

Há diversas maneiras de se aprender a fazer retratos que não por meio de uma escola de arte, como aconteceu com esses retratistas. Para os demais retratistas do Largo da Carioca, fazer retratos consiste em uma habilidade manifestada e/ou treinada em algum momento, em geral na adolescência, voltada mais que tudo para o exercício de ocupação que garanta a sobrevivência, muitas vezes equiparável a distintas ocupações e substituível por quaisquer outras que se apresentem como mais rentáveis. Mas existem variações importantes em relação a como concebem o retratismo.

Uma parte desses retratistas sem formação escolar em artes aprendeu com alguém - com o pai, pintor; com o avô, pintor de retratos na Rua da Carioca; com um pintor de retratos conhecido seu. São estes que se referem a uma "tradição de retratismo" no Largo da Carioca, vendo suas atividades como continuidade dela e, por isso, com valor nem sempre aquilatado pelos demais retratistas com quem compartilham aquele espaço. Estes outros, por exemplo, que chegaram a frequentar a universidade, mais que tudo reclamam da diminuição no número de vendas e no preço dos quadros ao relatarem sua remoção para a área do convento, sempre lamentando serem equiparados a camelôs. Já os retratistas referidos a uma "tradição de retratismo" são os que apresentam, com maior indignação e contundência, argumentos em torno de um direito adquirido de permanência naquele local de onde 
foram retirados, que está baseado na antiguidade da prática do retratismo ali, efetuada há gerações. Na verdade, são estes pintores de retratos que preferem se referir à sua ocupação como retratismo, e se declarar retratistas, termo que às vezes também é utilizado por aqueles que estudaram pintura na universidade e raramente mencionado pelos que afirmaram ter aprendido a pintar sem cursar nenhum tipo de escola de arte e sem ter professor algum. ${ }^{14}$

De fato, os seis retratistas que não frequentaram uma escola de arte afirmam ter "aprendido sozinhos", em autodidatismo que sublinham como valor por atestar talento, dom, que os que precisaram de orientação, ou mesmo ensino formal de arte, não teriam: "Eu aprendi sozinho mesmo. Ninguém me ensinou não. Desde moleque eu pegava fotos de revista, jornais, essas coisas assim, e começava a desenhar igualzinho. Quando fui ficando mais velho, desenhava fotos da minha mãe e da minha irmã. Daí uma coisa leva a outra."

A distinção entre aprender sozinho ou não inverte, como mencionamos, aquela indicada pelos retratistas que frequentaram a universidade, que frisam sua formação em arte ou pintura, desvalorizando e apontando imperfeições nos retratos feitos pelos demais. Além do talento que o "aprender sozinho" demandaria, para chegar a resultados por tentativa e erro, a ousadia de apresentar trabalhos imperfeitos e dispor de senso de oportunidade para abraçar, quando necessário, a ocupação de retratista são apresentados como qualidades pelos que não estudaram formalmente artes plásticas, nem tiveram a orientação de alguém para fazer retratos:

Eu não precisei estudar para fazer isso que eu faço. Mas tem muita gente por aí que acha que é pintor de verdade. Sempre gostei de desenhar e pintar. Quando eu era criança, ficava desenhando os desenhos que passavam na TV. Sempre fui bom nisso. Aí, com o tempo, eu melhorei e passei a desenhar gente e, depois, passei a pintar retratos. Trabalhei um tempo como pintor de paredes e até de fotógrafo de casamento. Mas aí eu vim para cá, que é mais tranquilo. Aí cheguei e já fui fazer os retratos. No início eles ficavam meio ruins, mas agora já estão iguais aos do pessoal aí. ${ }^{15}$

Essa desvalorização dos mecanismos institucionais e dos tradicionais de formação para a prática do retratismo vincula-se também ao caráter não regulado dos modos de participação e de avaliação dos retratos em um mercado que opera não apenas ali, no Largo da Carioca, mas em diversos outros lugares. Quase todos os retratistas do Largo da Carioca, com mais ou menos frequência, fazem retratos em outros pontos da cidade, e em outras cidades. Consideram haver sempre alguma demanda por retratos, especial- 
mente por turistas, que circulam naquela área, mas estão concentrados em outros pontos do Rio de Janeiro, às vezes em praias valorizadas e distantes do seu local de moradia, onde não teriam condições mesmo de se instalar. A maioria desses retratistas, inclusive por conta da diminuição da venda com a transferência para perto do convento, conjuga, com maior ou menor intensidade, o trabalho ali com a feitura de retratos em outros lugares. Sobretudo os que declararam ter aprendido a pintar sozinhos teriam encontrado nesse mercado, formado principalmente por turistas, o incentivo para começar a trabalhar fazendo retratos.

Eu já tinha trabalhado pintando paredes, [como] servente de pedreiro, chaveiro, ajudante de padeiro, tinha feito de tudo um pouco. Aí, num carnaval, eu comecei a andar pelas praias daqui do Rio, passava nos bares ali na Gávea, em Ipanema, andava o Rio todo a pé, carregando minhas coisas, e oferecia o serviço. Sempre tinha algum turista que queria. O pessoal de fora do Brasil compra bem. Fazia cada retrato por quarenta, cinquenta reais. [...] Aí fiquei trabalhando como carregador de um supermercado que acabou falindo, e acabei vindo para cá.

Tanto para os retratistas que aprenderam sozinhos quanto para os demais, fazer retratos é atividade que se alterna e muitas vezes se conjuga com outras. Como referimos, para os que estudaram artes plásticas, essa justaposição de atividades é bem diferente, o leque de possibilidades de trabalho para além do retratismo sempre coincide com práticas artísticas adequadas à sua formação ou consideradas por eles como afins. Para os que não tiveram essa formação - mais jovens e em geral sem terem completado o ensino médio - fazer retratos é uma opção dentre outras atividades que não exigem escolaridade ou especialização e que, na grande maioria das vezes, não têm relação com práticas artísticas. Eles de fato procuram trabalho nas mais diferentes áreas, e estão dispostos a assumir outros postos a qualquer momento.

Os retratistas que aprenderam a pintar retratos com alguma pessoa indicam, contudo, que não gostariam de "mudar de profissão", embora reconheçam sua inclinação para interromper esta atividade que valorizam e com a qual se identificam. De qualquer forma, tanto para eles quanto para os que declaram ter aprendido a fazer retratos sozinhos, aquela ocupação é concebida como passageira, porque poderia no limite atrapalhar vínculos de trabalho mais estáveis e que consideram mais interessantes.

Claro que se surgisse algo melhor eu sairia, mas por enquanto não tenho nada em vista não. A única coisa que tem na minha carteira de trabalho é carregador 
de supermercado, porque o resto foi tudo sem assinar. Então, quando eu faço entrevista [para conseguir trabalho], o pessoal acha estranho eu não ter nada na carteira. Isso já aconteceu muito. Aí eu digo que pinto retratos e é aí mesmo que o pessoal não me leva a sério. Teve uma vez que eu fiz uma entrevista para uma empresa de vigilância, aí o rapaz me perguntou se eu era daqueles hippies que ficam vendendo brinco com pena e fazendo retratos.

\section{O fim da linha}

Os retratistas que não tiveram formação em artes plásticas, embora reconheçam que suas atuais atividades são muitas vezes "mais tranquilas" e "menos pesadas" que outras que já exerceram, têm na empresa modelo corrente para avaliar o retratismo exercido na rua, salientando a inexistência de vínculos estáveis de trabalho, o desregramento e a informalidade. Já os retratistas com formação em arte costumam explicar sua insatisfação com o trabalho na rua contrastando-o com o do ateliê.

Possuir um ateliê consiste frequentemente em item que atesta a própria condição de artista em diversos ambientes de artes plásticas. Em Dabul (2001) há descrição de como, já no processo de formação de artistas plásticos que se dedicam à chamada pintura contemporânea, a demarcação, a expansão e a individualização do espaço de trabalho acompanham bem de perto a constituição da identidade de artista. Noutra direção, dispor de um ateliê é sinal do afastamento dos artistas da situação de venda, comumente concebida como operação inadequada para eles já que, idealmente, deveriam concentrar-se na dimensão e nos procedimentos estritos da criação artística. Com efeito, em pesquisa junto a artistas plásticos que trabalham ao lado de artesãos em feira de artesanato no nordeste do Brasil (Dabul, no prelo), são apresentadas evidências do quanto a participação na venda é carregada de tensão para os artistas plásticos que puderam, em algum momento, prescindir delas, dedicando-se exclusivamente à pintura e delegando a empresários ou galeristas, por exemplo, as preocupações e os procedimentos práticos da venda de sua produção - situação diferente da dos retratistas do Largo da Carioca com formação em artes plásticas. Para estes, além de espaço de trabalho valorizado e indicativo de sua inserção no métier, o ateliê está sempre associado à presença de clientes e a operações de exposição e venda de suas pinturas.

O afluxo de clientes ao local onde os trabalhos estão disponíveis é na verdade item fundamental para que os retratistas com formação em artes considerem o ateliê situação ideal de trabalho. Antes de se estabelecerem 
pintando retratos nas ruas, tendo no Largo da Carioca pouso mais constante, esses retratistas em algum momento trabalharam em ateliês de outros artistas ou dispuseram por um curto período de seus próprios ateliês, não encontrando condições para mantê-los. Ao descreverem os ateliês onde trabalharam, referem-se vivamente ao fato de a clientela dirigir-se "espontaneamente" para eles, sem que fosse necessário o apelo que costumam fazer para que contratem seu trabalho. E essa afluência de clientes ser regulada pelo artista, que estabelece dia e hora para ela, aparece como importante índice de autonomia: "O bom do ateliê é que é igual ao de um escritório de advocacia. Você fica sentado e o cliente aparece. E se você não quer trabalhar, você não vai".

O afluxo em direção ao ateliê, além de associado à autonomia e a menos desgaste físico, resulta, segundo indicaram, em maiores ganhos que o trabalho na rua. E, diferente do constrangimento que em muitos setores da produção artística acompanha qualquer indicação das intenções comerciais da arte, é frequente esses retratistas revelarem a expectativa e o prazer de venderem muito e bem o seu trabalho: "Tenho certeza de que se eu tivesse condições de montar um ateliê, comprar um material bom e divulgar, eu ia estar ganhando era muita grana". Mas ao contrário do que tendemos a sublinhar no estudo da produção de artistas das classes populares, a venda não se restringe à operação que garante a sobrevivência e a reprodução das condições de trabalho dos artistas. Por meio da venda o valor artístico do trabalho desses retratistas é aquilatado e realizado, seu reconhecimento sendo concretizado no preço pago pelo cliente. ${ }^{16}$

Também vinculado ao estabelecimento e à realização do preço, encontramos aquele sonhado afluxo dos clientes em direção ao artista e à sua produção que, mais que indicativo de autonomia, vem a ser índice importante do reconhecimento e da demonstração do valor dos seus trabalhos. O oferecimento contínuo de retratos a transeuntes desinteressados atesta a inexistência desse afluxo na rua.

Eu queria mesmo era ter um ateliê. Quando era mais moço, cheguei a trabalhar de ajudante em alguns ateliês. Trabalhei até com pessoal que ganhava grana mesmo. No ateliê tudo fica mais fácil. Você faz tudo do teu jeito, na hora que você quer e não precisa ficar vendendo quadro como se fosse água mineral. No ateliê só vai quem quer, quem está interessado de verdade.

Esse direcionamento e o correspondente interesse do cliente são próprios de uma centralidade do artista e do seu trabalho, supondo em boa medida a aceitação do que ele estabelece como arte. Norbert Elias (1995) 
propõe que as distintas configurações que arte e artistas assumem historicamente estão correlacionadas a variações do lugar do artista diante de seu público e, contrastando "artistas artesãos" e "artistas livres" — os que hoje encontraríamos de modo preponderante - vincula as relações dos artistas com seu público às relações de classe. Segundo Elias, o "artista artesão" dependia das demandas de um público de aristocratas que não tinha o conhecimento da sua arte, mas sim o poder de estabelecer o que teria ou não valor artístico. Isto porque pertencia à classe à qual os artistas estariam subordinados, da qual dependeriam para sobreviver e para a qual criariam seu trabalho. Já o artista livre dessa submissão teria o poder de criar produtos e padrões artísticos que seu público estaria interessado em conhecer e, eventualmente, em aceitar. ${ }^{17}$

Por conta de sua origem social e da trajetória que puderam construir já desde o início de sua formação, os retratistas do Largo da Carioca que estudaram na universidade sistematicamente se viram impossibilitados de dirigir sua produção para aqueles que concebem como pertencentes ou vinculados a classes sociais privilegiadas, ou que reconhecem ter o poder de julgar o valor propriamente artístico de seu trabalho. Se não encontram constrangimentos da mesma ordem daqueles sofridos pelos "artistas artesãos" descritos por Elias, descolando razoavelmente os conteúdos e as intenções do que produzem das pressões da hierarquia social, diferente dos "artistas livres", eles estão submetidos a um público que não reconhecem como capacitado para avaliar o que produzem.

Foco constante de descontentamento para esses retratistas com formação em artes, o fato de o artista ter que "correr atrás de clientes" não fornece, isolado, a dimensão da frustração que encontram por não verem seu trabalho valorizado devidamente. Esses retratistas com formação em artes plásticas não reconhecem em turistas e transeuntes que circulam pelo Largo da Carioca e nos outros lugares onde vendem retratos nem interesse nem capacidade de avaliação do que seja ou não arte. E é a ausência dessa capacidade que faz com que a especificidade dos trabalhos que oferecem em comparação com os dos demais retratistas não seja identificada pelos eventuais clientes: "E eu vou fazer o quê? Se o cliente não sabe olhar e ver quem tem os melhores quadros, aí já não é culpa minha".

Ter acesso apenas a público desqualificado potencializa o descontentamento dos retratistas em face da relação que têm com ele, diametralmente oposta à idealizada e descrita como própria do ateliê, e mais distante ainda da que artistas bem-sucedidos experimentam ao catalisar clientes qualificados dispostos a perceber o valor e o significado de seu trabalho. O peso de lidarem com clientes desqualificados poderia ser atenuado, como artistas 
plásticos que trabalham na rua em outras circunstâncias afirmam fazer, impondo sua própria avaliação do valor de sua produção aos seus clientes. Em Fortaleza, Ceará, artistas plásticos que trabalham nas ruas vendendo pinturas para turistas, muitos deles "gringos peões que não sabem nem ver uma obra de arte", mencionam manter de modo inabalável os preços que estabelecem: "Não baixo de jeito nenhum. E eles acabam comprando". ${ }^{18}$ No caso dos artistas plásticos retratistas do Largo da Carioca, a não seletividade de sua clientela não é compensada por mecanismos desta natureza. Demandas pela sobrevivência impõem-se com força e produtos similares são oferecidos em profusão por retratistas "que não conhecem nada de arte". O fim da linha está ali, atestado pela dupla frustração de terem que se submeter a um público desqualificado, que nem "sabe olhar".

\section{Tantas linhas}

O Largo da Carioca apresenta conjunção muito especial das formas de se praticar arte e viver dela. De um lado, jovens estão aptos a reproduzir ofício artístico - o retratismo - herdado de outros retratistas, valorizado por eles e que gostariam que tivesse continuação, mas que se encontram sempre na iminência de ter de abandonar em função da sobrevivência. De outro lado, há retratistas que manipulam uma técnica por acreditarem ter um dom, mas não encontram condições de trabalho e existência que os levem a prolongar seu vínculo com ela. Finalmente, encontramos homens maduros, artistas plásticos que exercem o que consideram ser apenas uma modalidade do métier especializado ao qual se dedicam desde sempre, e ao qual pretendem continuar a se dedicar indefinidamente. ${ }^{19}$

Diferente dos retratistas mais jovens que trabalham no Largo da Carioca, para os retratistas com formação em artes plásticas, o trabalho na rua não é situação a ser desdobrada em outras mais adequadas, mas sim atestado de frustração em relação a uma carreira que não puderam construir. Acompanhar o relato que fazem desse processo nos ajuda a compreender o significado, para eles, de estarem ali, agregando o incômodo de verem sua arte e sua condição de artistas serem colocadas seguidamente em questão pelo convívio com aqueles indivíduos "despreparados" e que produzem objetos considerados por eles sem qualidade, e pelos clientes que julgam incapazes de fazer a devida distinção entre eles. Trata-se de atentar para a diversidade de mecanismos de reconhecimento e de não reconhecimento da arte e dos artistas, como aquele que os situa em posição de inferioridade em relação aos atores sociais que, estes sim, gostariam de ter como interlocutores. 
Se buscarmos vínculos entre essa situação de trabalho na rua com a trajetória desses artistas plásticos, nós nos depararemos com indivíduos que estudaram artes em instituição voltada para a formação de artistas e cuja produção se direcionava para outros atores sociais que não aqueles que hoje vêm circulando no Largo da Carioca e nos outros locais onde oferecem seu trabalho. A impossibilidade de alcançarem quem poderia eventualmente avaliar a qualidade do que produzem configurou-se claramente com o tempo, e já estava determinada pelas condições que encontraram para conduzir sua formação como artistas plásticos ainda no curso universitário que escolheram. Com efeito, não dispunham de recursos materiais para investir plenamente na sua formação e no seu exercício profissional, experimentando intermitências e lacunas inadequadas se confrontadas com os mecanismos naturalizados de constituição de carreiras de artistas. Também não desfrutavam a inserção social capaz de permitir acionar relações sociais para transitar com segurança e prestígio nas redes constituídas por e em torno de indivíduos com outra origem social, e que detinham de fato o acesso às chances de ter sua arte devidamente avaliada, e não raro o poder de proceder a essa avaliação.

Essa formação e a contínua prática nas artes plásticas estendem-se para bem além do processo de exclusão vivido por esses retratistas, que podemos relacionar diretamente com mecanismos que impedem a participação e ao mesmo tempo constituem o campo artístico, ${ }^{20}$ lado a lado com aqueles que, também na arte, confirmam hierarquias sociais apoiadas nas relações de classe. No caso estudado, o significado dessa formação e da prática nas chamadas artes plásticas está atrelado também a outras modalidades artísticas que permitem que o retratismo exista nas ruas, e a atores sociais que produzem ou compram retratos.

De fato, a ênfase que encontramos na forma de aprendizado da pintura de retratos, compartilhada de alguma maneira por todos os retratistas do Largo da Carioca, nos remete à descrição feita por P. Burke (1988), desenvolvendo proposição de R. Redfield (1956), da transmissão da "grande tradição". Essa tradição se diferenciava, segundo Burke, da pequena tradição também por conta das instituições - dentre elas a universidade - que garantiam mecanismos formais e restritivos de transmiti-la. Ao contrário da pequena tradição, difundida amplamente por mecanismos informais, a grande tradição não era acessível às classes populares. Mas se para os retratistas do Largo da Carioca que tiveram acesso à formação universitária ela consiste em fator de sua superioridade diante dos demais retratistas, eles sabem o quanto essa formação não é suficiente para que construam uma carreira artística como gostariam, por exigir recursos materiais e inserção social que não possuem. Ao mesmo tempo, esses retratistas sublinham o quanto a formação e o título 
universitário, junto ao próprio campo artístico, nem sempre representam caução para carreiras e produção artística. ${ }^{21}$ Para amplos setores das artes contemporâneas, a formação universitária em artes está longe de garantir qualidade no trabalho artístico ou condições para a construção de carreiras. ${ }^{22}$

A perda do valor dessa formação é, em alguma medida, aquilatada pelos próprios retratistas que frequentaram a universidade quando indicam o caráter agora não seletivo, mais aberto, que a universidade pública vem assumindo no Brasil, acessada também por indivíduos das classes populares. De qualquer modo, é significativo o reconhecimento da especificidade das chamadas artes plásticas diante de outras formas de produção artística das classes populares, como o chamado artesanato. E é com frequência que se apresentam vinculadas a um saber muito valorizado e de transmissão altamente restrita, mesmo quando praticadas por artistas de origem popular e que não tiveram acesso à universidade. ${ }^{23}$ Em certa medida, junto às classes populares, a formação universitária em artes plásticas, tão exclusiva, constitui uma das modalidades de capacitação para essa prática artística disseminada e apreciada. Longe, portanto, de terem suas trajetórias referidas apenas ao insucesso em função dos mecanismos inadequados de formação artística destinados a indivíduos com sua origem social, os retratistas que frequentaram a universidade encontram, em distintas áreas da vida social, diversas e conflituosas possibilidades de sua arte e sua condição de artistas virem à luz e serem objetos de avaliação.

Na verdade, a situação experimentada hoje por esses artistas retratistas conjuga tensões profundamente associadas à arte e que caracterizam, podemos afirmar, a ampla realidade de artistas empobrecidos e/ou sem reconhecimento junto aos atores sociais que eles gostariam de ver valorizando sua produção. Como a arte adquire diferentes e numerosas configurações, encontramos não raro artistas temendo ou se deparando com a equiparação de sua produção à de atores sociais que eles não consideram artistas, mas com os quais têm que compartilhar mercado de objetos voltado para transeuntes e turistas - no caso que estudamos, o de artistas que pintam retratos em ruas do Rio de Janeiro. Embora não reconheçam nos que fazem essa equiparação do seu trabalho com o de outros retratistas qualquer competência para o julgamento artístico do que produzem, esses enganos do seu público têm relevância para eles, e o contexto no qual são produzidos prolonga-se por envolver suas necessidades de sobrevivência e o desejo de trabalhar com sua arte. Associado a isso, artistas também permanecem por vezes eternamente - aceitando a legitimidade do julgamento de atores sociais e instituições aos quais não têm de fato pleno acesso, colocando-se em posição de dependência e inferioridade. 
Estamos nos referindo, portanto, por sua durabilidade, extensão e sua frequência, a ocorrências possivelmente mais "típicas" que as carreiras artísticas bem-sucedidas e as circunstâncias em que artistas veem seus trabalhos sendo avaliados da maneira que julgam adequada por indivíduos e instituições que teriam, para eles, condições para tanto. Acontecimentos ligados à pobreza e ao insucesso são dificilmente incluídos nos esquemas de compreensão da arte, e poucas vezes são construídas questões que os vinculem à hierarquia social sem que percam a complexidade advinda da dispersão das práticas artísticas por tantos lugares e com sentidos que nem imaginamos.

Introduzir no estudo da arte de artistas das classes populares o cuidado de Elias (1995) a respeito de para quem ela é produzida, das relações sociais e do que chama de estrutura fixa, que estão na base desses vetores de comunicação na produção da arte, reduz o automatismo no estabelecimento de um campo de estudo próprio da chamada arte ou cultura popular e no desconhecimento dos vínculos que possui com a chamada arte de elite. ${ }^{24}$ Tratar como dado de pesquisa a existência de uma hierarquia de vetores operada tanto por artistas como por pesquisadores da arte, que recorta o que é arte e quem é artista em boa medida de acordo com o lugar da hierarquia social (Bourdieu 2007) - e não apenas da topografia do campo artístico — para o qual eles estão dirigidos, talvez seja a maior exigência que nos coloca o estudo de situações em que artistas das classes populares, como de resto todos os artistas, estão convivendo seguidamente com o risco de sua arte não ser vista como arte.

Lígia Dabul é professora do Programa de Pós-Graduação em Sociologia, da Universidade Federal Fluminense. E-mail: <ldabul@uol.com.br>

Rodrigo Barreto é bacharel em Ciências Sociais pela UFF e funcionário do Senado Federal - Distrito Federal, Brasil. E-mail: < ro_sousabarreto@hotmail.com> 


\section{Notas}

* Os dados sobre os retratistas nos quais este artigo se baseia foram obtidos em pesquisa realizada durante 2008 e 2009 no âmbito do projeto "Criação artística como prática social", apoiado pelo CNPq e vinculado ao Nectar - Núcleo de Estudos Cidadania, Trabalho e Arte da Universidade Federal Fluminense, coordenado por Lígia Dabul. Em Barreto (2009) foram feitas análises preliminares dos retratistas do Largo da Carioca do Rio. Agradecemos ao CNPq e à Faperj pelo apoio à pesquisa, e a School of Social Sciences da University of Manchester, onde parte da redação do artigo foi feita.

${ }^{1}$ Norbert Elias (1995) já chamava a atenção para esse procedimento de "espiritualização" da arte, de supressão do que de fato a constitui e possui de humano, e de suas consequências, particularmente para o estudo sociológico dos artistas e do que produzem.

${ }^{2}$ A definição de H. Becker (1982) de arte popular inclui um tanto dessa correspondência.

${ }^{3}$ A Operação Choque de Ordem, iniciada em 2009, consistiu então em uma série de ações promovidas pela Secretaria de Ordem Pública da Prefeitura do Rio de Janeiro, visando, segundo ela, 'pôr fim à desordem urbana'. Controversas, e contando com frequência com reações da população afetada, as ações da Prefeitura incluíram em diversos locais da cidade o cadastramento de trabalhadores que faziam uso de espaço público em suas atividades e sua alocação, ou realocação, para exercê-las.

4 Ver em D. Pommier (1998) o quanto a semelhança define e valoriza o retrato como modalidade artística, sobretudo na pintura. Não podendo desenvolver aqui o tema, vale indicar que a cópia do retrato, portanto cópia de uma cópia, consiste em prática vazada por uma série de convenções perpassadas por essa valorização da representação embelezada do suposto referente do referente. Ver em Petra T. Kalshoven (2010) outra situação em que a avaliação de quanto uma cópia é bem-sucedida está vinculada a critérios outros que não apenas o da similaridade. Sergio Miceli (1996) amplifica a análise do significado social do retrato no estudo dos "investimentos sociais" da pintura de retratos feita ao longo da carreira do pintor brasileiro Candido Portinari.

${ }^{5}$ Carla Dias (2006), em estudo sobre as paneleiras de Goiabeiras, estado do Espírito Santo, Brasil, foca uma modalidade de oposição igualmente estranha a boa parte da produção artística das classes populares - a que distingue uso e significado. Baseada em dados de pesquisa e em formulações de C. Steiner (2006), afirma que a polarização não opera nem faz sentido na prática de artistas populares e nem na avaliação que fazem de seus trabalhos.

${ }^{6}$ Esse grupo de retratistas do Largo da Carioca é extremamente instável. Por razões que veremos adiante, sua composição e seu tamanho variam muito. O feitio que encontramos no momento da pesquisa, portanto, dificilmente veremos repetido. 
${ }^{7}$ Os demais têm entre 25 e 42 anos, com concentração na faixa dos 30 anos.

${ }^{8}$ Os dados dessa pesquisa nos foram fornecidos pelos retratistas por meio de conversas, entrevistas e questionários, e obtidos também pela observação direta da sua situação de trabalho no Largo da Carioca.

${ }^{9}$ Ver em Dabul (2001) descrição de despesas que constituem a - e diferenciam as chances de - construção de uma carreira artística a partir de inserção em outra instituição voltada para a formação de artistas plásticos, a Escola de Artes Visuais do Parque Lage, também no Rio.

${ }^{10}$ Ao se referirem ao crescente número de turistas no Rio de Janeiro, os retratistas mencionam mais que tudo turistas estrangeiros. D. Greenwood (1977) indica, por exemplo, o quanto, embora não com a devida ênfase, a expansão do turismo em escala internacional há muito vem sendo percebida e seus efeitos estudados.

${ }^{11}$ Nelson Graburn diferencia, entre os suvenires adquiridos por turistas, os conectados com sua própria viagem e os referidos a "other past phenomena" (2000). Os retratos produzidos pelos retratistas que estudamos parecem consistir em suvenires do primeiro tipo. De qualquer forma, correspondem à descrição de Michael Hitchcock (2000) "Suvenires são sinais das viagens dos turistas, sendo, portanto, frequentemente tidos como provas tangíveis de onde ele ou ela esteve". Ao lado disso, são também, para ele, "mementos de uma experiência fora do comum", assemelhando-se a "fotos de férias" - a que o retrato corresponderia de maneira especial, mas agregando o carater "handmade" particularmente valorizado por turistas nos suvenires (Littrel, Anderson \& Brown, 1993).

${ }^{12}$ A concomitância de atividades artísticas com outras, nem sempre vinculadas a elas, é comum entre artistas plásticos. Ver estudo a este respeito em D. Throsby e A. Zednik (2011).

${ }^{13}$ Observar que, se para esses retratistas trabalhar na rua consiste em indicativo da impossibilidade de realização do artista, este não é necessariamente o ponto de vista dos artistas que trabalham na rua. Para diversos deles, o trabalho na rua pode estar associado a um estilo de vida alternativo, e a uma deliberada crítica das formas oficiais e comerciais de praticar a arte, como descrito por S. Harrison-Pepper (1994). Para tantos outros artistas, a rua seria o lócus adequado para uma série de iniciativas da arte contemporânea - ver a este respeito R. Rezende e F. Scovino (2010).

${ }^{14}$ Mas neste artigo estamos nos referindo indistintamente a todos os que vendiam retratos no Largo da Carioca no momento da pesquisa como retratistas.

${ }^{15}$ E. Cohen (1993) refere-se à situação em que a arte voltada para turistas levaria ao abandono de antigas técnicas, em razão da necessidade de simplificação, ainda que permaneçam valorizadas nos "bastidores". No caso que estudamos, os contornos que a simplificação de técnicas "tradicionais" ou "acadêmicas" da feitura de retratos assumem podem indicar o caráter não necessariamente uniforme por meio do qual é experimentada por seus diferentes produtores. 
${ }^{16}$ É comum a inclusão da venda, e mais diretamente do preço realizado na venda, no rol de mecanismos por meio dos quais artistas plásticos aferem e materializam o valor de sua produção (Dabul, no prelo).

${ }^{17}$ A respeito dos retratos, J. Woodall (1997:7) menciona aspectos da centralidade do artista nas transformações da sua relação com seus retratados: "Retratos mostrando amigos e familiares do artista existem desde o século XV, pelo menos, mas no final do século XIX, o retratismo 'de vanguarda' restringiu-se marcadamente a imagens não encomendadas dessas categorias de retratados. Isto incrementou a autoridade do artista, tornando o merecimento de ser retratado dependente de uma relação com ele ou ela".

${ }^{18}$ A favor de nosso argumento de que o que importa para os artistas é, mais que o tipo de cliente, a relação que estabelecem com os clientes, há uma série de depoimentos dos retratistas do Largo da Carioca que tiveram formação em artes plásticas sobre como a venda para turistas esteve presente também em momentos prósperos de sua trajetória, como quando dispunham de ateliê e/ou de boa clientela. Na verdade, a produção para turistas parece acompanhar de fato a continuidade da prática artística de amplo contingente de indivíduos. Dentre eles, encontram-se os que tentam se inserir em processos de aprendizagem em ambientes de ensino e prática da chamada arte contemporânea, ainda que, na maior parte das vezes, essa produção seja severamente desvalorizada e concorra para a inviabilização da construção de uma carreira artística em tais contextos (Dabul 2001).

${ }^{19}$ A importância da pintura de retratos em face de outras práticas artísticas é consideravelmente variável na história da pintura. Sua relação com o lugar social do pintor de retratos pode ser aferida em A. Rosenthal (1997), no estudo das pintoras de retrato na Europa do século XVIII, cuja prática, concebida como atividade mimética meramente repetitiva, era confrontada com a masculina "verdadeira criatividade" característica de outras modalidades de pintura, como a histórica.

${ }^{20} \mathrm{Ou}$ seja, a sua impossibilidade de efetuar tomadas de posição na "rede de relações objetivas [...] entre posições" (P. Bourdieu 1996:261), o campo artístico.

${ }^{21}$ Ver, por exemplo, depoimento de retratista a respeito da profusão de atores sociais e mecanismos de produção e circulação dos artistas plásticos no Rio de Janeiro já nas décadas de 1970 e 1980: "A Belas Artes aqui tinha uma tradição muito conservadora, muito elitista. O pessoal que estava pensando em mudar a arte, a pintura, essas coisas mais modernas, esse pessoal do Helio Oiticica, estava em outros cantos. A gente ali estava mais preocupado com estilo, técnica, beleza, História da Arte e em entrar para o mercado, no fim das contas".

${ }^{22}$ Essa formação pode constituir mesmo empecilho para o reconhecimento do valor artístico da produção dos que se submeteram a ela (Dabul 2001).

${ }^{23}$ Artesãos e artistas plásticos que trabalham na mesma feira de artesanato em Fortaleza, Ceará, por exemplo, remetem boa parte de suas distinções a uma superioridade das artes plásticas e dos seus produtos, quadros, ou pinturas, e esculturas, 
associando-a a um "conhecimento superior", a uma "história antiga" e a "grandes artistas".

${ }^{24}$ Questionar esse automatismo não significa minimizar a oportunidade do estudo da cultura e da arte populares, inclusive dos mecanismos de produção de sua liberdade em relação à chamada cultura e arte de massa e à chamada cultura e arte de elite.

\section{Referências bibliográficas}

BARRETO, Rodrigo. 2009. Pintores de retrato. Quando a rua é o ateliê. Monografia de Graduação em Ciências Sociais, Universidade Federal Fluminense.

BECKER, Howard. 1982. Art worlds. Berkeley/Los Angeles/London: University of California Press.

BOURDIEU, Pierre. 2007. A distinção: crítica social do julgamento. São Paulo e Porto Alegre: Edusp/ Zouk. - 1996. As regras da arte. Gênese e estrutura do campo literário. São Paulo: Companhia das Letras.

BURKE, Peter. 1988. Popular culture in early modern Europe. Aldershot: Wildwood.

COHEN, Erik. 1993. "Introduction. Investigating tourist arts". Annals of Tourism Research, 20:1-8.

DABUL, Lígia. 2001. Um percurso da pintura. A produção de identidades de artista. Niterói: Eduff.

- [no prelo]. "Artes plásticas em feira de artesanato: venda, criação e os olhos para ver a arte". Sociologia \& Antropologia. Revista do Programa de Pós-Graduação em Sociologia e Antropologia da Universidade Federal do Rio de Janeiro.
DIAS, Carla. 2006. Panela de barro preto. A tradição das paneleiras de Goiabeiras, Vitória - ES. Niterói: Mauá Editora.

ELIAS, Norbert. 1995. Mozart. Sociologia de um gênio. Rio de Janeiro: Jorge Zahar Editor.

GRABURN, Nelson. 2000. "Foreword". In: Michael Hitchcock \& Ken Teague (eds.), Souvenirs: the material culture of tourism. London: University of North London. pp. xii-xvii.

GREENWOOD, Davydd J. 1976. "Tourism as an agent of change. A Spanish Basque case". Annals of Tourism Research, III(3):128-142. . 1977. "Culture by the pound: an anthropological perspective on tourism as cultural commodization". In: Valene L. Smith (ed.), Hosts and guests. The anrhropology of tourism. Philadelphia: University of Pennsylvania Press. pp. 129-138.

HARRISON-PEPPER, Sally. 1994. "Outside in the city: street performers in New York's Washington Square Park". In: Michael D. Hall et al. (eds.), The artist outsider. Creativity and the boundaries of culture. Washington/ London: Smithsonian Institution Press. pp. 332-347. 
HITCHCOCK, Michael. 2000. "Introduction". In: Michael Hitchcock \& Ken Teague (eds.), Souvenirs: the material culture of tourism. London: University of North London. pp. 1-17.

KALSHOVEN, Petra T. 2010."Things in the making. Playing with imitation". Etnofoor, Imitation, 22(1):59-74.

LITTRELL, Mary Ann; ANDERSON, Luella F. \& BROWN, Pamela J. 1993. "What makes a craft souvenir authentic?" Annals of Tourism Research, 20(1):197-215.

MICELI, Sergio. 1996. Imagens negociadas. Retratos da elite brasileira (1920-1940). São Paulo: Companhia das Letras.

POMMIER, Édouard. 1998. Théories du portrait. De la Renaissance aux Lumières. Paris: Gallimard.

REDFIELD, Robert. 1956. Peasant society and culture: an anthropological approach to civilization. Chicago: University Press.

REZENDE, Renato \& SCOVINO, Felipe. 2010. Coletivos. Rio de Janeiro: Circuito. ROSENTHAL, Angela. 1997. "She's got the look! Eighteenth-century female portrait painters and the psychology of a potencially 'dangerous employment'". In: Joanna Woodall (ed.), Portraiture. Facing the subject. Manchester/New York: Manchester University Press. pp. 147-166.

STEINER, Christopher B. 2006. "The art of the trade: on the creation of value and authenticity in the African art market". In: Howard Morphy \& Morgan Perkins (eds.), The anthropology of art. A reader. Malden: Blackwell Publishing. pp. 454-465.

THROSBY, David \& ZEDNIK, Anita. 2011. "Multiple job-holding and artistic careers: some empirical evidence". Cultural Trends, 20(1):9-24.

WOODALL, Joanna. 1997. "Introduction: facing the subject". In:__. (ed.), Portraiture. Facing the subject. Manchester/ New York: Manchester University Press. pp. 1-25. 
Resumo

A partir da descrição da trajetória de retratistas com formação em artes plásticas que trabalham nas ruas do Rio de Janeiro, este artigo discute a constituição da condição de artista por atores sociais das classes populares. São trazidos para a análise vínculos entre espaços sociais apartados - de um lado, aquele onde esses artistas tiveram sua formação artística e para onde gostariam de estar produzindo sua arte e, de outro, aquele em que interagem com outros retratistas que consideram desqualificados e com quem disputam clientela e espaço de trabalho. A disseminação e a diversidade de configurações que práticas artísticas assumem e a maneira por vezes tensa por meio da qual convivem indicam os limites da compreensão da experiência desses artistas plásticos a partir exclusivamente das suas impossibilidades de inserção no chamado campo artístico. O artigo enfatiza como concepções de arte e de artista que operam em processos muito restritivos de formação de artistas plásticos incidem extensivamente nas formas pelas quais, em diferentes contextos, artistas das classes populares se especificam e a arte é avaliada. Essas concepções também trespassam o significado que atribuem à venda de seus produtos e à sua relação com clientes, e o modo como aferem a capacidade de os clientes compreenderem a sua arte.

Palavras-chave Retratismo, Retratista, Artista, Artes Visuais, Carreiras Artísticas, Arte.

\section{Abstract}

Starting from a description of the trajectory of portrait artists with degrees in fine art who work in the streets of Rio de Janeiro, this article discusses the constitution of the artist condition by social actors from the working classes. The analysis relies on links between distant social spaces - on the hand, those in which these artists were formally trained and for which they would like their art to be produced, and, on the other, those in which they interact with other portrait artists that they deem to be unqualified and with whom they compete for clients and work space. The dissemination and diversity of configurations assumed by artistic practice and the sometimes tense way in which they coexist indicate the limits for comprehending the experience of these artists, based exclusively on the impossibility of their insertion in the so-called artistic field. The article emphasizes how conceptions of art and the artist that hold sway in the very restrictive processes of the formal training of fine artists have an extensive effect on how artists from working class backgrounds, in different contexts, define themselves and evaluate art. These conceptions also exceed the meaning that they attribute to the sale of their products and their relationship with clients, as well as the way they judge their clients' ability to comprehend their art.

Key words Portrait art, Portrait artist, Artist, Visual arts, Careers in art, Art. 